\title{
Cidadania e envelhecimento em Parintins/AM: Entre a convivência social e os serviços públicos ${ }^{1}$
}

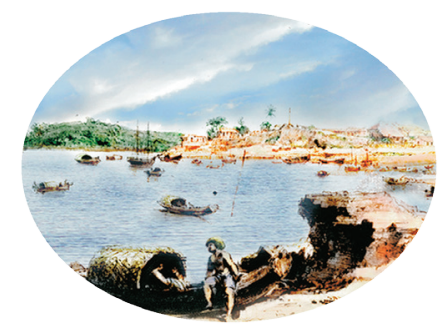

Valmiene Florindo Farias Sousa*

\begin{abstract}
Resumo
Este artigo discute os resultados da nossa pesquisa de mestrado, que analisou a implementação dos direitos do Idoso em Parintins (AM). O alcance do objetivo implicou a análise da construção e efetivação da Política Municipal do Idoso e a implementação do Programa Municipal de Atenção Integral ao Idoso. Esse processo de desvendamento dos direitos aos idosos em Parintins (AM), conduz a apreensão desta realidade e sua articulação com a criação de programas de convivência criados para o desenvolvimento de atividades sociais, físicas e de entretenimento que são serviços destinados à pessoa idosa.
\end{abstract}

Palavras-chave: Cidadania; envelhecimento; direitos sociais.

\begin{abstract}
This paper discusses the results of our research Masters, which reviewed the implementation of the Rights of the Elderly in Parintins (AM). The achievement of the objective involved examining the construction and execution of the Municipal Policy for the Elderly and the implementation of the Municipal Program of Integral Attention to the Elderly. This process of revealing the rights of older people in Parintins (AM), leads to seizure of this reality and its connection with the creation of coexistence programs created for the development of social, physical and
\end{abstract}

\footnotetext{
*Assistente Social, Mestre em Serviço Social e Sustentabilidade na Amazônia, docente do curso de Serviço Social do ICSFZ/UFAM Campus de Parintins.
} 
entertainment services that are intended for the elderly.

Keywords: Citizenship; age; social rights.

\section{Introdução}

A partir do marco jurídico institucional na Constituição Federal, na Lei $n^{\circ} 8.842$, e na Lei no $0.741 / 2003$, o envelhecimento é considerado na ótica da garantia dos direitos humanos, o que pressupõe condições dignas de promover sua autonomia e integração. Em Parintins (AM) vivem mais de 6.000 idosos, protegidos pela Lei Municipal $n^{\circ}$ 0349/2005, Política Municipal do Idoso (PMI). Esta é base para a criação de serviços, dentre eles, o Programa Municipal de Atenção Integral ao Idoso com foco em ações na saúde, educação, assistência social, esporte e lazer para 3.725 idosos (urbana e rural). A implementação da legislação municipal se constituiu objeto da nossa dissertação de mestrado, cujos principais resultados são discutidos nesse artigo.

Conhecendo a fundo a dinâmica que envolve o Programa de Atenção Integral ao Idoso em Parintins que intervém de forma mais concreta com serviços e ações, se conjura um painel de como o poder público tem ou não empreendido esforços para realizar um trabalho qualificado e competente para a efetivação de uma realidade mais digna para seus usuários, ou seja, de sua cidadania.

O artigo se estrutura em três partes: A primeira discute as questões da pesquisa, objetivos, lócus, sujeitos e as escolhas metodológicas para a investigação do objeto. A segunda parte aborda os principais resultados da pesquisa que tratam da questão da implantação e implementação da Política Municipal do Idoso em Parintins. Em seguida, discorre-se sobre os marcos históricos, sociopolíticos e as ações de atendimento do Programa Municipal de Atenção Integral ao Idoso. A última parte é conclusiva e aponta análise da retórica e a da realidade do programa de maneira a deslindar as ações promotoras da cidadania para seus usuários, um cenário marcado pelas conquistas, impasses e desafios referentes ao processo de legitimação e 
efetivação dos direitos sociais de idosos no município em questão.

\section{O Estudo}

Este trabalho teve por objetivo analisar, os avanços e limites da implementação dos direitos do idoso em Parintins (AM) $)^{2}$ a partir da implementação do Programa Municipal de Atenção Integral ao Idoso, no período de 2005 a 2010.

No tocante à cidade de Parintins (AM), a Lei Municipal no 0349/2005, que dispõe sobre a Política Municipal do Idoso (anexo), serviu de base para a criação do Programa Municipal de Atenção Integral ao Idoso (PMAID), que

desenvolve ações de atendimento na área da saúde, educação, assistência social, esporte e lazer, com o objetivo de possibilitar ao idoso exercer suas condições de cidadão dentro da rede de serviços públicos e contribuir para a melhoria da qualidade de vida deste segmento (Relatório do Programa Municipal de Atenção Integral ao Idoso, 2008).

O Programa Municipal de Atenção Integral ao Idoso, desponta no município como ação de ampla abrangência e visibilidade em função dos núcleos instalados tanto na zona urbana do município (oito unidades) como também na zona rural (cinco unidades) - lócus da pesquisa - e do número de idosos atendidos (3.725 cadastrados).

A pesquisa caracterizou-se por uma abordagem qualitativa. Fizemos visitas aos 13 núcleos do programa para observações diretas preliminares e sequenciais e também para o contato com os sujeitos da pesquisa e posteriormente a realização das entrevistas com eles.

A amostra para a realização deste trabalho foi composta por uma pessoa que participou do processo de formulação da Política Municipal do Idoso em Parintins; duas pessoas que compõem a coordenação do Programa de Atenção Integral ao Idoso para conhecimento quanto à forma de gestão e implementação do programa; 13 monitores dos núcleos do programa. Pelo fato de considerarmos a necessidade de um olhar endógeno do processo de 
implementação da Política Municipal do Idoso em Parintins, entrevistamos um dos conselheiros municipais.

No que se refere à amostra relativa aos idosos usuários do programa para analisar a implementação a partir de suas percepções, foi representativa, composta por um idoso de cada núcleo, ou seja, 13 pessoas de um universo composto por 1.844 idosos assíduos nos diversos núcleos.

As informações qualitativas coletadas foram trabalhadas com sujeitoobjeto e não com mero objeto de análise - como consequência, a comunicação se faz pelo que há de implícito do que é explícito (DEMO, 2001).

Nessa perspectiva, na análise dos dados coletados, foram observadas as contradições, divergências e incongruências das informações recebidas. As formulações desenvolvidas refletiram não apenas as elaborações teóricoempíricas do pesquisador, mas contêm as contribuições dos que participam do trabalho, principalmente nas entrevistas realizadas nos núcleos da zona rural, em que os idosos manifestaram o desejo de formação de pequenos grupos para a discussão dos objetivos pretendidos na pesquisa. Dessa interação resultaram os dados que foram sistematizados.

\section{A Política Municipal do Idoso em Parintins: Implantação e Implementação}

A Lei n. 0349, de 7 de julho de 2005, instituiu a Política Municipal do Idoso em Parintins, sob a égide do Estatuto do Idoso, aprovado em $1^{\circ}$ de outubro de 2003. No artigo primeiro dessa lei, consta que ela visa a assegurar os direitos sociais das pessoas com idade superior a 60 anos, residentes no Município de Parintins, criando condições para sua associação, integração e participação na sociedade.

Como previsto na Política Municipal do Idoso em Parintins, a operacionalização dessas atribuições fica a cargo do órgão responsável pela assistência social, que, no caso parintinense, trata-se da Secretaria Municipal de Assistência Social e Trabalho (Semast).

Segundo a entrevista com uma das pessoas que esteve no processo de discussão da PMI, o processo de criação da Política Municipal em Parintins partiu das discussões no I Fórum de Direitos do Idoso de Parintins, de três dias, coordenado pelos técnicos e promovido pela secretária da Semast, no primeiro semestre de 2005, e que contou com presença e participação de 
diversas secretarias municipais: saúde, educação, cultura, turismo, dentre outras.

Nesse fórum foram realizadas tanto palestras (com temas sobre envelhecimento, atividades físicas, saúde e direitos) quanto grupos temáticos de discussão sobre a necessidade de criação de um programa específico para idosos. Segundo uma entrevistada, "foi explicado para os idosos o que era o programa e o que estava sendo colocado dentro daquela política municipal" (Entrevistada 1, pesquisa de campo, 2010). Na oportunidade também foi formatado o Programa de Atenção Integral ao Idoso, bem como escolhida uma coordenação e a definição da criação de núcleos na zona urbana e rural do município.

Conforme Entrevistada 1, a maior presença no fórum foi a de idosos, com mais de 200 participantes, inclusive da zona rural do município. Entretanto, a participação destes foi para o repasse de informações sobre o objetivo do programa que seria criado, muito embora alguns idosos tenham contribuído com algumas ideias e sugestões. A mesma relata o apoio do Executivo e Legislativo municipal tanto para a realização do evento quanto para a celeridade da aprovação e sanção da Política Municipal do Idoso. O prefeito era o senhor Frank Luiz Bi Garcia, que exercia o fim de seu primeiro mandato, mas reelegeu-se no pleito consecutivo. O governo do prefeito em questão tinha um forte apelo ao desenvolvimento de qualidade de vida e manteve apoio às iniciativas sociais para a defesa dos direitos dos idosos em Parintins, na ocasião da apresentação do plano integrado para o desenvolvimento da Política Municipal do Idoso.

O protagonismo das ações da primeira-dama do município de Parintins na área social é destacado na fala de muitos entrevistados, sejam eles idosos ou profissionais, quando se trata do Programa de Atenção Integral ao Idoso. Essa constatação revela campo fértil para analisar como a assistência social no município está vinculada, até mesmo imbricada, com a questão do fenômeno do primeiro-damismo no Brasil, que remonta aos idos da criação da Legião Brasileira da Assistência (LBA), em que as primeiras-damas eram sucessivamente as responsáveis por sua gestão e coordenação.

Nesse sentido, para Torres “[...] o Estado se exime da sua responsabilidade e da sua função de intervenção na chamada 'questão social', transferindo essa responsabilidade para a própria sociedade sob a direção das primeiras-damas” 
(2002, p. 22).

O processo de criação da Política Municipal do Idoso mostrou-se positivo, pois garante em âmbito municipal respaldo legal para as demandas decorrentes do aumento da população idosa e atribui responsabilidades principalmente para os setores governamentais no que se refere à estruturação de serviços, programas e projetos voltados às necessidades do segmento idoso. Para tanto, é necessário analisar como se processa a implementação da Política Municipal do Idoso no município.

No que se refere à implementação da Política Municipal do Idoso em Parintins, questionamos a entrevistada sobre a existência ou não de um avanço significativo, pós-criação da política, no que tange ao investimento governamental em programas, serviços e projetos em Parintins. Ela diz:

Eu penso que houve avanços só na questão de implantação de núcleos do Programa do Idoso, e que cresceu um pouco a procura do Benefício da Prestação Continuada. Eu vejo que os núcleos estão crescendo, mas eu vejo que falta alguma coisa, não sei bem o que é (Entrevistada 1, pesquisa de campo, 2010).

De fato não há em Parintins uma rede articulada de serviços públicos específicos para os idosos, mas sim, programas que já estavam sendo executados antes da criação da aprovação da Política Municipal do Idoso, como programas voltados para a saúde do idoso.

Outro ganho visualizado com a aprovação da Política Municipal do Idoso foi a criação do Conselho Municipal do Idoso, definido em lei como um dos órgãos responsáveis pela fiscalização das entidades de atendimento ao idoso. Segundo o artigo 53 do Capítulo III do Estatuto do Idoso, "compete aos Conselhos de que trata o art. $6^{\circ 3}$ desta Lei a supervisão, o acompanhamento, a fiscalização e a avaliação da política nacional do idoso, no âmbito das respectivas instâncias político-administrativas".

\section{PROGRAMA MUNICIPAL DE ATENÇÃO INTEGRAL AO IDOSO: Marcos Históricos, Sociopolíticos e Ações de Atendimento}


O Programa de Atenção Integral ao Idoso foi criado em 1994, na gestão do prefeito Enéias Gonçalves, mas na época havia poucos núcleos distribuídos em bairros da zona urbana da cidade. Entrevistamos uma das idosas que está desde o início da implantação do programa e destaca bem esse surgimento: "Esse grupo foi formado ainda na época do prefeito Enéias, era na rua, bem perigoso, aí depois quando ele saiu continuaram com o Bi. E eu estou desde o comecinho" (Idosa 1, pesquisa de campo, 2010).

O programa adquiriu maior visibilidade na gestão executiva do prefeito Bi Garcia - para isso, contribuiu de forma significativa o trabalho específico de coordenação da primeira-dama. No entanto, o programa tem a sua garantia legal baseada nos marcos normativos (Estatuto do Idoso), o qual indica a implantação de serviços por entidades de atendimento governamentais e não governamentais. Devem ser observados alguns requisitos, dentre estes: "Oferecer instalações físicas em condições adequadas de habitabilidade, higiene, salubridade e segurança”" (Estatuto do Idoso, Art. 48, no item I do Parágrafo único).

A partir da nova formatação do programa, os núcleos implantados em 1994 foram incorporados. Em 2005, quando da aprovação da Política Municipal do Idoso, o programa tem respaldo político através da legislação municipal, a qual garante a criação de programas e serviços voltados ao atendimento ao idoso em Parintins.

A política municipal aponta a criação não só do Programa Municipal de Atenção Integral em si, mas de ações, serviços e alternativas para a população idosa nas áreas da assistência social, saúde e educação, nos moldes de serviços especializados e compostos por articulação de ações intersetoriais, sendo resultado de conquistas históricas.

Concernente às primeiras ações para a criação do programa, as falas demonstram que se deram pela necessidade de implantar núcleos fora do ambiente da rua por favorecerem a insegurança para as atividades propostas (convivência e lazer). A partir desse momento (2005), inicia-se a instalação do Centro de Convivência do Idoso Pastor Lessa, que foi construído ao lado do Posto de Saúde Galliane, no bairro do Itaúna, periferia do município. Conforme 
os depoimentos, o bairro do Itaúna foi escolhido de forma estratégica por ser o maior bairro de Parintins em extensão e número de habitantes. Para os demais núcleos de atendimento, os espaços utilizados são praças, áreas de convivência de centros comunitários (barracões), centros sociais das paróquias e escolas.

A questão do espaço físico é um ponto marcadamente notado nas falas dos idosos e monitores que destacam que alguns espaços não oferecem ambiente adequado por não serem "próprios" e não terem condições de armazenar os produtos recebidos e produzidos (material de expediente ou artesanato.

O Programa de Atenção Integral à Pessoa Idosa tem como objetivo geral:

desenvolver ações por meio dos serviços socioassistenciais, socioeducativos e de desenvolvimentos de projetos de inclusão dos idosos e suas famílias, de acordo com as necessidades detectadas no âmbito social no município de Parintins. Possibilita ao idoso exercer suas condições de cidadão dentro da rede de serviços públicos, contribuindo para a melhoria de sua qualidade de vida (Relatório do Programa de Atenção Integral à Pessoa Idosa, 2009).

Com o objetivo definido, o Programa de Atenção Integral ao Idoso se aproxima dos objetivos de um dos serviços socioassistenciais definidos pela Resolução da Proteção Social (Resolução CNAS n. ${ }^{\circ}$ 109/2009). Segundo a Tipificação Nacional de Serviços Socioassistenciais, são considerados serviços de convivência e fortalecimento de vínculos o serviço para crianças até 6 anos, o serviço para crianças e adolescentes de seis a 15 anos, o serviço para adolescentes e jovens de 15 a 17 anos (Projovem Adolescente) e o serviço para idosos.

Embora haja evidência quanto à similaridade nos objetivos do Programa de Atenção Integral ao Idoso com os serviços socioassistenciais preconizados no Sistema único de Assistência Social, o programa não está atrelado à Proteção Básica de Assistência Social no que concerne às ações do Centro de Referência de Assistência Social (CRAS) em Parintins. O programa é uma ação isolada, com equipe específica e coordenada diretamente pelo gabinete da primeiradama, inclusive os recursos financeiros não derivam da secretaria de origem, 
como demonstra a coordenação do programa:

Não existe verba direcionada para o programa. O programa é sustentado pelo executivo municipal e está incluído na saúde do idoso (Entrevistada 2, pesquisa de campo, 2010) A gente não tem verba. O programa do idoso ele é municipal e não tem verba, e não tem como a prefeitura separar um valor para o programa, não funciona assim. Eu falo que a gente trabalha sem dinheiro mesmo. Só que o que acontece: com a divulgação do trabalho, e foi uma coisa que alavancou muito, é que as pessoas começaram a prestar atenção no idoso. (Entrevistada 3, pesquisa de campo, 2010).

Quanto ao atendimento direto aos idosos e à responsabilidade em executar os serviços e ações do Programa de Atenção Integral ao Idoso, são atribuições da equipe de monitoramento (leia-se: monitores). A equipe é composta por 18 pessoas, sendo majoritariamente mulheres (com somente dois homens); eles possuem idade variando de 25 a 50 anos, com grau de escolaridade predominantemente até o ensino médio e são pagos pela Secretaria Municipal de Saúde.

Dos 13 monitores entrevistados, somente um havia tido experiência anterior no trabalho com grupo de idosos, com curso de Cuidador de Idosos, três tinham experiência nos movimentos ligados às pastorais da Igreja Católica e os demais nunca haviam trabalhado, sendo esse o "primeiro emprego".

Nas observações diretas das atividades realizadas em um dos núcleos de atendimento na pesquisa de campo, presenciamos o trabalho da equipe do Núcleo de Apoio à Saúde da Família (Nasf) realizando conjuntamente com os monitores atividades recreativas e de lazer. Havia profissionais de educação física, assistente social, psicólogo e fisioterapeuta. Entretanto, ao questionarmos um idoso participante do núcleo sobre a visita da equipe de profissionais naquele núcleo, ele diz: "São raras as vezes que esse pessoal vem visitar a gente, mas quando eles vem é muito bom" (Idoso 2, pesquisa de campo, 2010).

A pesquisa aponta a ausência de infraestrutura nos espaços em que são realizadas as atividades. As falas dos monitores revelam certa angústia quanto às limitações para o trabalho derivadas dessa falta ou inadequação do espaço. 
As principais falas se referem ao tamanho do espaço ("O barracão é pequeno pra quantidade de idosos que nós temos”) (Monitor 4, pesquisa de campo, 2010); infraestrutura ("a nossa dificuldade é local que não tem cadeira, não tem som”) (Monitor 1, pesquisa de campo, 2010.

Apesar das dificuldades apontadas quanto ao local inadequado e ao material insuficiente, a equipe de monitores se desdobra, num esforço pessoal, para garantir aos idosos - dentro dos limites institucionais - o melhor possível. Foi constatado que há uma grande dedicação deles numa tentativa de superar os entraves postos pelas dificuldades no trabalho.

\section{O PROGRAMA MUNICIPAL DE ATENÇÃO INTEGRAL AO IDOSO: Evidências e Percepções pelo Olhar dos Usuários}

O Programa de Atenção Integral à Pessoa Idosa, atualmente, possui 3.725 idosos cadastrados e 1834 idosos frequentadores, divididos em zona urbana e zona rural. A idade mínima para participar do programa é de 60 anos. Além das atividades nos núcleos, os idosos contam com o atendimento na Semast em relação à previdência social, à emissão de carteiras do idoso e de denúncias referentes à violência contra o idoso. Em relação a este último, é realizado em parceria com o Conselho Municipal do Idoso.

Devido à grande demanda no atendimento aos idosos e à procura para a instalação de núcleos na zona rural, houve a necessidade de se dividir em núcleos, para que todos os idosos do município se tornassem usuários das atividades desenvolvidas no programa, sendo oito na zona urbana e cinco na zona rural respectivamente:

Ao perguntarmos os motivos que levaram os idosos entrevistados a frequentar o programa, as falas revelam que o incentivo de amigos foi o que mais contribuiu para o ingresso no grupo, conforme falas a seguir: "Foi o incentivo dos amigos, que me disseram que eu deveria participar, pois sou sozinho, sabe? Eu venho mais pra cá para me divertir, fazer amigos" (Idoso 10, pesquisa de campo, 2010); outros destacam que passaram a frequentar o grupo por interesse próprio no sentido de transformar a vida sedentária em uma vida mais ativa: "Entre ficar em casa sem fazer nada, sentindo dores, e ter 
alguma atividade física, é bem melhor ir para a atividade" (Idosa 1, pesquisa de campo, 2010). Este último dado é interessante, pois se constata que o trabalho desenvolvido no programa transformou os grupos em uma realidade que figura entre uma alternativa à ressocialização do idoso, de melhorias de sua qualidade de vida.

Principalmente na zona rural, percebemos uma mudança na rotina dos idosos que antes tinham uma referência de tempo livre: o deitar na rede, a conversa com amigos para tomar café e o cuidar da horta. Essas atividades não podem ser tidas como inapropriadas ou atividades que ficam aquém das propostas pelo programa. Em conversa com idosos no núcleo, as antigas atividades ainda são preservadas e as que eles participam foram incorporadas às já existentes, sendo mais uma a preencher o tempo livre.

Ao perguntarmos sobre as atividades realizadas no programa e sua percepção, os idosos apontam contentamento ao realizá-las e como elas até recuperam o sono perdido, aumentam o círculo de relacionamentos e garantem a oportunidade de informações. Dentre as atividades apontadas estão as atividades físicas, as atividades dançantes, as atividades manuais e as palestras.

A contribuição do programa para a integração social do idoso, ainda que não haja atividades específicas nessa direção, pode ser considerada positiva. A saída do ambiente doméstico, a vivência grupal, a socialização de experiências, o aprendizado de coisas novas, o lazer, as atividades físicas e todas as competências desenvolvidas a partir daí podem contribuir para que o idoso se sinta mais seguro na relação com o "outro", o que é um facilitador da integração.

Os idosos, ao serem questionados sobre o trabalho dos monitores, apresentam uma avaliação positiva e afirmam que suas expectativas são plenamente satisfeitas. A relação entre monitor e idoso é próxima - em alguns momentos, percebemos até demonstrações de afeto e carinho entre eles.

A inserção dos idosos no programa garante uma série de mudanças que indiscutivelmente podem ser potencializadoras de uma vida mais ativa, menos solitária, com elevação da autoestima, de alegria de viver, de sentimento de valorização, aumento de amizades e até mesmo mobilização quando um dos idosos chama a atenção para a necessidade de aglutinar outras pessoas para que 
o programa não chegue ao término.

A autora Gohn (2001) concorda com essa afirmação quando fala das possibilidades da participação e a importância da autoestima, da autoimagem e das representações sobre sua própria vida nos espaços de convivência para idosos.

No entanto, para possibilitar o "exercício de cidadania, o reconhecimento do idoso como sujeito de direitos, assegurar os direitos sociais do idoso" e tantas outras expressões nesse mesmo sentido presentes nos objetivos do programa, esses ganhos devem estar na dimensão pessoal e também coletiva, como ressalta Paz (2000). Esse avanço para o plano coletivo é imprescindível, pois, embora haja um aparato legal de proteção à pessoa idosa em Parintins, a condição do idoso na sociedade não é adequada às suas necessidades e somente no coletivo poderá engendrar um empenho pela consecução de direitos e pela garantia dos já conquistados.

\section{Considerações finais}

Este estudo partiu de concepções de cidadania e da noção de direitos, especificamente dos direitos relativos à população idosa, sem antes nos reportarmos às considerações a respeito de como a velhice segundo Beauvoir (1990) é uma categoria construída socialmente e tem sido tratada e classificada de maneira diferente, de acordo com períodos históricos e com a estrutura social, econômica e política de cada povo.

A pesquisa apontou que o processo de formulação da política municipal de Parintins teve a participação ativa dos movimentos sociais, dos idosos e o protagonismo da condução dos trabalhos pela Secretaria Municipal de Assistência Social e Cidadania.

Também os dados revelam que há um reconhecimento (por parte de quem vivenciou o processo de formulação e dos conselheiros municipais do idoso) que a Política Municipal do Idoso representa um avanço legal no município. Contudo, também é sinalizada a necessidade da implementação de uma rede com os serviços já existentes na cidade de Parintins e também a ampliação dos mesmos serviços. É importante destacar também a ligação desses aspectos com a dimensão do papel da sociedade civil organizada, cabendo a 
esta a tarefa de exercitar a sua capacidade organizativa e propositiva no sentido de cobrar do poder público a implementação dessa lei, principalmente no que se refere ao papel do Conselho Municipal do Idoso, que está em Parintins em fase de estruturação e vivencia ainda a desmobilização para então cobrar a implementação da Política Municipal do Idoso.

No que se refere aos condicionantes históricos que impulsionaram a criação do Programa de Atenção Integral ao Idoso, destaca-se que a Política Municipal do Idoso aponta para a criação do programa municipal e indica os moldes em que devem ser formatadas as suas propostas (ações intersetoriais). Entretanto, ainda persiste a ideia de que o programa é fruto de um Estado paternalista, provedor, com ações primeiro-damistas, incorporando a ideologia historicamente produzida pelas classes dominantes.

A implementação das ações de atendimento do Programa Municipal de Atenção Integral ao Idoso a partir da visão dos executores e do público-alvo revela semelhanças, os quais destacam a importância que elas exercem na vida dos idosos usuários, possibilitando-lhes participação, convívio e ocupação. As observações realizadas nos grupos permitem identificar, a partir do relato dos idosos, que a participação nas atividades propostas pelo programa reduz problemas decorrentes da solidão, intensifica contatos sociais e desenvolve novas capacidades.

Entretanto, as ações de atendimento exigem do gestor público uma organização orçamentária de destinação de recursos específicos para o programa que dariam autossustentabilidade das ações, no que se refere a recursos materiais, recursos humanos e de espaço físico condizente às necessidades dos idosos usuários.

A contribuição para a socialização dos idosos é patente, até mesmo por ser um dos poucos espaços de socialização no município. Para Bulla (2008) programas de convivência se constituem em espaço de convivência, de trocas afetivas, de formação de amizades entre as pessoas idosas e dá suporte significativo no sentido de descobrir os iguais no processo de socialização, construindo um elo de pertencimento individual e coletivo.

A pesquisa não aponta um empenho acerca da promoção da cidadania do idoso, principalmente no que tange ao compromisso da gestão do programa em torná-lo uma política pública permanente no município. Se, por um lado, 
a direção política do programa não explicita compromisso com a sustentação física e financeira dele, que é uma das diretrizes da Política Nacional do Idoso e que pode contribuir na efetivação dos direitos, por outro, o idoso - numa visão funcional - sente-se desobrigado a essa participação.

A promoção do envelhecimento ativo e saudável é perceptível na fala, no olhar, nas atitudes dos idosos. E se expressa quando falam da motivação de sair de casa, da superação de estados depressivos, da melhora das condições físicas e também está implícito quando apontam a condição de ser idoso como uma importante etapa da vida, mencionam as conquistas em relação às gerações passadas e da possibilidade da concretização do sonho de liberdade.

Em síntese, embora o Programa de Atenção Integral ao Idoso no município de Parintins contribua a para a conquista da integração do idoso na sociedade, esta ainda encontra-se incipiente no que se refere à participação cidadã desse usuário que, como demonstra a pesquisa, ainda desconhece seus direitos e ainda não participa ativamente dos processos decisórios sobre a implementação desses mesmos direitos, .

Há limites e entraves para tal, conforme descrito ao longo desta pesquisa. No entanto, "entre a situação real e a situação potencial, abre-se espaço para o compromisso social e político para a ação” (SÁ, 1997, p. 20). Nesse sentido, estudos e pesquisas constantes sobre esse segmento e as políticas públicas destinados à eles em contextos variados como o amazônico tem-se apresentado como desafio para profissionais e pesquisadores do Serviço Social.

\section{Notas}

${ }^{1}$ Elaborado a partir da dissertação de Mestrado "Envelhecimento em Parintins-AM: Um enfoque para o Programa de Atenção Integral ao Idoso". Manaus, 2011. Com orientação da Profa. Cristiane Bonfim Fernandez. Programa de Pós Graduação em Serviço Social e Sustentabilidade na Amazônia da Universidade Federal do Amazonas.

${ }^{2}$ Essa cidade do interior amazonense, é insular, com pouco mais de 100 mil habitantes, se transforma com a chegada do mês de junho. Nessa época, quando a cidade apresenta-se dividida pelas cores azul e vermelha dos bois-bumbá Caprichoso e Garantido, Parintins é palco da maior manifestação cultural do Norte brasileiro, o Festival Folclórico de Parintins. O município localiza-se à margem direita do Rio Amazonas, numa área de 5.978 quilômetros quadrados e fica 369 quilômetros da capital, Manaus.

${ }^{3}$ Todo cidadão tem o dever de comunicar a autoridade competente qualquer forma de violação 
a essa lei que tenha testemunhado ou de que tenha conhecimento (Lei $\mathrm{n}^{\circ} 10.741$, de $1^{\circ}$ de outubro de 2003).

\section{Referências}

BEAUVOIR, Simone. A velhice. Rio de Janeiro. Nova Fronteira, 1990.

BRASIL. Lei 10.741, de 1 de outubro de 2003. Dispõe sobre o Estatuto do Idoso. BULLA, L. C., SOARES, E.S, KIST, R.B. Cidadania, pertencimento e participação social de idosos. In: Ser Social 21: Revista do Programa de Pós-Graduação em Política Social. Brasília.UNB, 2008.

DEMO, Pedro. Pesquisa e Informação Qualitativa: aportes metodológicos. 2. ed. São Paulo. Papirus Editora, 2001.

PARINTINS. Lei Municipal no 0349 de de 07 de julho de 2005. Dispõe sobre a Política Municipal do Idoso.

PAZ, Serafim, et al (Orgs). Os programas sociais para os idosos no processo de exclusão x participação social. IN: Violência e Exclusão Social. Série Estudos e Pesquisas, v.5, Niterói: EDUFF, 2000. p. 57-72.

RELATÓRIO. Atividades do Programa de Atenção Integral ao Idoso. Secretaria Municipal de Assistência Social e Trabalho, Parintins, 2009.

SÁ, V.M.T.P.L. O novo velho e as politicas sociais: e o setor de saúde, como se manifesta? 1997. Dissertação de Mestrado em Saúde Pública. Escola Nacional de Saúde Pública, Rio de Janeiro, 1997.

TORRES, Iraildes Caldas. As primeiras-damas e a assistência social: relações de gênero e poder. São Paulo: Cortez, 2002. 